This item was submitted to Loughborough's Research Repository by the author.

Items in Figshare are protected by copyright, with all rights reserved, unless otherwise indicated.

\title{
Experimental testing of structural arrangement on window response to long- duration blast
}

PLEASE CITE THE PUBLISHED VERSION

https://doi.org/10.1016/j.engfailanal.2021.105304

PUBLISHER

Elsevier

VERSION

AM (Accepted Manuscript)

\section{PUBLISHER STATEMENT}

This paper was accepted for publication in the journal Engineering Failure Analysis and the definitive published version is available at https://doi.org/10.1016/j.engfailanal.2021.105304.

LICENCE

CC BY-NC-ND 4.0

\section{REPOSITORY RECORD}

Monk, Sarah, and Simon Clubley. 2021. "Experimental Testing of Structural Arrangement on Window Response to Long-duration Blast". Loughborough University. https://hdl.handle.net/2134/13739341.v1. 


\title{
EXPERIMENTAL TESTING OF STRUCTURAL ARRANGEMENT ON WINDOW RESPONSE TO LONG-DURATION BLAST
}

\author{
Sarah Monk ${ }^{a}$ \\ BEng(Hons) PhD \\ *Simon K Clubleyb \\ BEng(Hons) MBA PhD EUR ING CEng MICE MInstP \\ a Consultant Blast Engineer \\ Crossley Consult, \\ Southwark, London, SE11 8ND, UK \\ Email: Sarah.Monk@crossleyconsult.com \\ ${ }^{*}$ b Senior Lecturer in Structural Engineering \& Blast Engineering \\ School of Architecture, Building and Civil Engineering, \\ Loughborough University, Leicestershire, LE11 3TU, UK \\ Email: S.Clubley@lboro.ac.uk Tel. 01509222909 \\ ${ }^{*}$ Corresponding author
}

Original submission date: June 2020

Revision: Jan 2021 


\section{ABSTRACT}

1 In an explosion, window failure can occur at large standoff distances resulting in a

2 significant hazard radius. Up to $80 \%$ of injuries in an urban blast are estimated to be

3 caused by glass failure and subsequent fragmentation. Annealed glass, found in many

4 older buildings, shatters instantly into angular shards lacerating the skin on impact and

5 causing significant injury. Large explosions produce long-duration blast environments

6 in the far-field. These events are high-energy and produce impulses which can cause

7 window failure several kilometres away from the detonation. Data from long-duration

8 blasts indicate window failure is highly dependent on glazing aspect ratio, area and

9 other structural support parameters. In this paper, influence of glazing aspect ratio,

10 support conditions, material strength and the blast environment on window failure was

11 experimentally investigated. Twenty full-scale experiments quantified parameter

12 influence on glazing response to long-duration blast. Importantly, experimental

13 repeats exhibited notable data spread demonstrating that glazing response should be

14 quantified primarily by probability of failure and not deterministic methods

15 characteristic of current custom and practice. Repeat reference data sets are of

16 considerable scientific value to both practitioners and researchers particularly in this

17 difficult field of engineering where access to suitable test facilities remain limited. 


\section{INTRODUCTION}

On 19th April 1995, between $1800 \mathrm{~kg}$ and $2300 \mathrm{~kg}$ of ammonium nitrate and fuel oil mixture (ANFO) detonated outside the Alfred P. Murrah Federal building, Oklahoma. Window failure occurred further than $1.6 \mathrm{~km}$ away from the detonation. A large proportion of windows in the area were manufactured using monolithic annealed glass. This shattered instantaneously into angular shards that lacerated skin on impact, causing significant injury. Such shards were thrown further than $3 \mathrm{~m}$ into buildings close to the explosion, a dangerous and potentially life-threatening hazard. 167 deaths and 592 injuries were recorded, $39 \%$ of injuries were glass related. Victims generally suffered multiple soft tissue injuries like lacerations, contusions and abrasions [1]. Trawinski et al. [2] estimated up to $80 \%$ of injuries in an urban blast are due to glass failure. In 1998, studies by Claber [3] showed approximately $90 \%$ of UK buildings contained some annealed glazing. While modern facades generally utilise toughened, heat-strengthened or laminated glass, monolithic annealed glass remains common particularly in older buildings and represents a high hazard should an explosion occur. The widespread prevalence of annealed glazing internationally and the commensurate threat to infrastructure due to high-energy blast and fragmentation effects was recently demonstrated in Beirut ( $4^{\text {th }}$ August 2020 ) by the severity of glazing damage recorded at considerable range from the point of large yield detonation (estimated $0.50-1.12 \mathrm{kt}$ TNT eq. [4]).

In an explosion, product gases under high pressure and temperature, rapidly expand, forcing surrounding ambient air outwards inducing a blast wave, shown in Figure 1 as an idealised shock. The pressure increase from ambient conditions is termed overpressure. Large explosions like the Oklahoma event, produce a longduration blast wave in the far-field typically defined by a positive phase duration 
greater than $40 \mathrm{~ms}$. This blast environment produces large impulses causing window failure several kilometres away despite low overpressure presenting a significant hazard radius. In August 2015, an estimated 800 tons of ammonium nitrate detonated in Tianjin, China [5] causing critical damage to windows five and a half kilometres away [6]. Window damage to a residential building in close proximity to the detonation is shown in Figure 2 [7]. It can be readily assumed that all windows received the same blast pressure due to the explosion magnitude. Furthermore, it is also a reasonable assumption that the glass was the same age, thickness, had the same framing and was monolithic annealed. Despite these common characteristics some glass failed and some survived. Analysis indicates a higher proportion of smaller windows survived compared to larger windows, indicating the influence of area on window survival. From the same imagery it was determined that higher aspect ratio glazing had a higher failure probability than square glazing of a similar area. Material strength which can vary by more than $\pm 25 \%$ [8] (dynamic design strength of annealed glass subjected to blast loads is $80 \mathrm{MPa}$ [9]), was the likely cause of inconsistent failure of windows with the same dimensions. The image of damage caused by the Tianjin explosion indicates window response to blast loading can be highly variable, dependent on material strength and key structural parameters particularly glazing area and aspect ratio.

Importantly, very little long-duration blast testing has been conducted to determine glazing response to highly dynamic loading. Several tests were undertaken between 1950 and 1980, but data collected were limited to qualitative descriptions. Many windows consisted of a sash and muntin construction and no dimensions were quoted. In 1951, a building with $3 \mathrm{~mm}$ and $6 \mathrm{~mm}$ toughened glass windows was subjected to an estimated free-field overpressure of $14 \mathrm{kPa}$. The majority of $3 \mathrm{~mm}$ thick glass on the front of the building failed however all $6 \mathrm{~mm}$ thick glass located on the building front 
remained undamaged. All $3 \mathrm{~mm}$ thick windows on the sides of the building were broken, despite only being subjected to the free-field overpressure. Frames containing thicker glass were more heavily damaged which was attributed to a longer break time, resulting in a higher load transferral to the frame [10]. In 1955, three houses were subjected to $\mathrm{P}_{\mathrm{s}} 12 \mathrm{kPa}$ [11]. No information on glazing dimensions was provided. In all three houses, glass in the front windows was destroyed. Most side windows were blown in and glass in the rear windows "suffered some damage".

In the 1973 Eskimo II trials [13], 26 windows with varying structural parameters were subjected to three different long-duration blast environments. Glazing aspect ratio ranged from $1: 1$ to $1: 2.1$ and area varied between $0.54 \mathrm{~m}^{2}$ and $2.8 \mathrm{~m}^{2}$. The $2-3 \mathrm{~mm}$ thick annealed glass was supported using a range of different conditions. All ten windows subjected to $\mathrm{Ps}_{\mathrm{s}} 3.7 \mathrm{kPa}$ and impulse of $292 \mathrm{kPa}$.ms failed (impulse estimated assuming idealised triangular blast wave). Seven of the eight windows subjected to $P_{s}$ 2.8kPa and impulse $252 \mathrm{kPa}$.ms failed. In comparison all eight windows subjected to $\mathrm{P}_{\mathrm{s}} 1.5 \mathrm{kPa}$ and impulse $152 \mathrm{kPa}$.ms survived. Despite a large variation in structural parameters like aspect ratio and glazing area, the blast environment appeared to govern window failure or survival.

Modern long-duration blast trials require use of specialist facilities such as the air blast tunnel (ABT) at MOD Shoeburyness, UK (Figure 3)[14]. The ABT is one of a small number of facilities worldwide capable of testing full-scale structural response to long-duration blast waves. In a series of full-scale experimental trials, Johns and Clubley[15,16] varied glazing thickness, exposed area, aspect ratio and support conditions, concluding that influence of support conditions and aspect ratio was dependent on area, thickness and proximity to the glazing failure threshold. Elastically 
94 framed windows recorded a lower probability of failure compared to rigid framing which Johns argued was a result of stress reduction due to elastic framing. It was concluded that glazing response to long-duration blast was dependent on framing conditions, glazing area, thickness and aspect ratio.

More recent experimental research into glazing response to blast loading has mainly focussed on short-duration blasts and the use of laminated glass to mitigate risks due to blast loading. Due to the high cost involved, many researchers complete a limited series of explosive trials with few to no repeats and often only as a curtailed benchmark for computationally biased and abstract analysis. Highly variable material strength, which is extremely difficult to model numerically, means rigorous experimental testing is necessary to understand the complexities of glazing response to blast loading. Nawar et al.[17] performed three long-duration shock tube tests on laminated glazing to benchmark an FEA numerical study. Results indicated that a thinner interlayer deflected further under blast loading and is more susceptible to tearing. Heatstrengthened glass plies resulted in reduced deflection indicating a stiffer arrangement when compared to annealed glass plies in the same laminate configuration. Hooper et al.[18] completed four full-scale short-duration blast tests on laminated glass and compared results to an FEA study. Analysis of digital image correlation (DIC) data indicated that the deflected panel shape had a flat central region with little deformation and areas of high deformation near panel edges. Deflection was not symmetrical, a

114 larger deflection often occurred at the bottom outer corner of the panel. In three fullscale shock tube tests on laminated windows, Lusk et al.[19] determined that glazing thickness influenced displacement, with thicker windows displacing less than thinner

117 glass exposed to the same blast environment. Chen et al.[20] completed nine fullscale blast tests on four-point supported laminated glazing assemblies, finding that 
increasing window thickness from $8 \mathrm{~mm}$ to $10 \mathrm{~mm}$ decreased peak displacement by approximately $20 \%$. Wei et al.[21,22] used FEA (LS-DYNA) to simulate in isolation the behaviour of old, new laminated and monolithic glazing subjected to a short-duration blast. It was found probability of failure was higher for older glass compared to new glass panel structures. Increasing glass thickness and decreasing area both decreased probability of failure. For new annealed glass, an aspect ratio of 1:1.4 provided the greatest blast resistance and a window of 1:2.8 aspect ratio the least. Zhang et al. [23] discussed the importance of research into the blast performance of monolithic glass windows due to the "ubiquitous use in structural facades and windows for decades". The authors conducted full-scale arena tests of monolithic tempered glass panels, recording panel deformation and fracture characteristics when subjected to blast loading. Test results were compared to ASTM and UFC standards, and the authors concluded that the standards may not provide accurate estimations of toughened glass performance, especially in an impulsive (long-duration) blast environment.

This paper builds directly upon Johns' important research[15,16] quantifying influence of structural parameters on glazing response to long-duration blast loading. Monolithic annealed, $4 \mathrm{~mm}$ thick glass represents the UK minimum window specification and therefore and importantly, the worst-case damage in a blast event. This thickness was implemented in all trials. Influence of glazing aspect ratio, support conditions and peak overpressure was investigated in an extensive ABT trial schedule over two phases. The effect of each parameter on glazing response was analysed and ranked to determine its significance in governing commensurate failure. 


\section{EXPERIMENTAL SET-UP AND INSTRUMENTATION}

Two identical glass samples were tested for each explosive trial, with 40 windows in total tested over 20 trials (Table 1). In all trials, $4 \mathrm{~mm}$ thick annealed glass with area $0.89 \mathrm{~m}^{2}$ was used. In Phase 1, four aspect ratios were tested, 1:1, 1:1.3, 1:1.7 and 1:2, with four repeats for each arrangement. Only rigid support conditions were tested and a blast environment with peak free-field pressure $\left(P_{s}\right) 14 \mathrm{kPa}$ implemented. In Phase 224 glass samples were tested at two lower blast environments, Ps $5 \mathrm{kPa}$ and $10 \mathrm{kPa}$. Aspect ratios 1:1, 1:1.3 and 1:2 with both rigid and elastic support conditions were tested.

Steel test cubicles used successfully in Johns' experimental trials[15], were installed in the $10.2 \mathrm{~m}$ diameter section of the $A B T$, normal to the blast wave (Figure 4). Modular housings enabled frames to be constructed separately then fitted to test cubicles facilitating a quick turnaround allowing two blast trials per day. All sub-frame assemblies were rigidly connected to the test cubicle using bolts torqued to $40 \mathrm{Nm}$. The rigid frame (Figure 5a) was designed to represent a perfectly rigid support condition. Glass was restrained by steel frames bolted together against $7 \mathrm{~mm}$ spacers to ensure uniform restraint. Thick foam of $3 \mathrm{~mm}$ thickness compressed to $1.5 \mathrm{~mm}$, was adhered to both sides of the glass to prevent stress concentrations due to uneven frame surfaces. Elastic framing implemented structural sealant Sika SG500 to enable out-of-plane glass rotation representing pinned support conditions (Figure 5b). A full pressure history was recorded using three Endevco 8510-50 static pressure gauges and two Endevco 8515C-50 reflected gauges (gauge locations shown in Figure 6). Reflected pressure $(\operatorname{Pr})$ gauges were attached to the test cubicle front surface in line with window centres. All pressure gauges were analysed at a $1 \mathrm{MHz}$ sample rate. Two high-speed cameras in each test container captured glazing response. Phantom 2512 
cameras ( $\mathrm{C} 1$ and $\mathrm{C} 2)$ recorded crack location and break time. Phantom V711 cameras C3 and C4 tracked deflection gauge movement enabling measurement of central deflection (shown respectively in Figure 7). All cameras utilised frame rates of 75,000 frames per second (fps). All instrumentation was triggered by fibre optic at driver detonation to ensure a common time scale.

\section{RESULTS \& DISCUSSION: REFERENCE BLAST ENVIRONMENT}

Overpressure, $P_{s}$ and free-field impulse, $\left(I_{s}\right)$ were recorded $3 \mathrm{~m}$ upstream of the test cubicles. Excellent consistency was observed in the trial series for both pressure and impulse, specifically in the initial part of the blast wave. Slight variations in impulse in the later part of the overpressure history was attributed to gauge noise or flow field turbulence behind the blast wave front. Free-field pressure and impulse histories for trials at $14 \mathrm{kPa}, 10 \mathrm{kPa}$ and $5 \mathrm{kPa} \mathrm{Ps}_{\mathrm{s}}$ are shown for reference in Figure 8. Values of $\mathrm{Ps}_{\mathrm{s}}$, $I_{s}$ and positive phase duration $\left(\mathrm{t}_{\mathrm{d}}\right)$ for each trial are detailed in Table 2. Good agreement and high levels of consistency were observed for all blast parameters. Maximum repeatability was recorded for $P_{s} 14 \mathrm{kPa}$ trials with mean $P_{s} 13.4 \pm 0.1 \mathrm{kPa}$, $t_{d}$ $100 \pm 1 \mathrm{~ms}$ and Is $690 \pm 7 \mathrm{kPa}$.ms. Ps $5 \mathrm{kPa}$ trials exhibited reduced consistency in Ps compared to $14 \mathrm{kPa}$ trials $(6.3 \pm 0.3 \mathrm{kPa})$ but recorded $\mathrm{td}_{\mathrm{d}}(48 \pm 1 \mathrm{~ms})$ and $\mathrm{l}_{\mathrm{s}}$ values were highly consistent $\left(223 \pm 4 \mathrm{kPa}\right.$.ms). This increased $\mathrm{Ps}_{\mathrm{s}}$ variation (standard deviation of $5 \%$ ) can be attributed to blast wave perturbations due to turbulence at low pressures.

Shock wave reflections produced by the test containers within the contained environment of the ABT led to increased measurements of free-field pressure and impulse. An initial rise observed after the peak pressure was a function of changing light levels in the ABT due to dust translation and overall Endevco 8510-50 gauge sensitivity, which are sensitive instrumentation with respect to intense light and heat. 
191 This behaviour has been observed in multiple ABT trials dependent on the power envelope and environmental conditions. A second observable free field peak was caused by air particles reflecting off the container front surface and travelling upstream. Further subsequent peaks in the free-field pressure history can be attributed to characteristics of the ABT and driver charge design. The ABT diameter does not increase linearly but in three stages, shown in Figure 3. These large-scale shock tube regions cause decreases in air density and pressure causing peaks and troughs in the pressure trace while reshaping the wave towards an intended near planar Mach front. Any final peaks in the pressure history at comparative late times can be attributed to shock reflections from the rarefaction wave eliminator (RWE) travelling back upstream. Reflected overpressure histories for all trials (shown in Figure 8) demonstrated good consistency between trials and for both test cubicles, indicating a uniform pressure wave. Reflected peak overpressure $\left(P_{r}\right)$ and reflected impulse $\left(I_{r}\right)$ for each trial are detailed for reference in Table 3.

Mean reflected pressure, $\mathrm{Pr}$ values for $14 \mathrm{kPa}, 10 \mathrm{kPa}$ and $5 \mathrm{kPa}$ blast environments were $27.2 \pm 0.9 \mathrm{kPa}, 20.1 \pm 1.0 \mathrm{kPa}$ and $12.4 \pm 0.7 \mathrm{kPa}$ respectively. The largest standard deviation was $6 \%$ of the mean for the low power, low pressure $5 \mathrm{kPa}$ blast environment; arguably the most difficult and challenging environment for the $A B T$ to reliably recreate. Total reflected impulse was equally consistent with a maximum standard deviation $2 \%$. The peak value was recorded from the average overpressure in the first $2110.5 \mathrm{~ms}$, removing gauge noise. An increase in reflected overpressure between $0.5 \mathrm{~ms}$ and $1.5 \mathrm{~ms}$ after blast wave arrival was due to pressure build up and reflections within 213 steelwork on the front of test containers. It cannot be assumed the glass experienced 214 the same reflections; consequently, the initial peak was used to characterise the 215 reflected blast wave. 


\section{RESULTS \& DISCUSSION: GLAZING RESPONSE}

In this section the effect of aspect ratio, support conditions and peak overpressure on window failure is analysed and quantified. Three long-duration blast environments were defined in the $A B T$ environment substantiation and will be subsequently referred to in terms of $\operatorname{Pr}$ (see Table 4). Three samples remained unbroken for reflected pressures of $12 \mathrm{kPa}$. All windows subjected to higher peak pressures failed. Out of those that survived, two comprised elastic frames and one rigid while each window retained a different aspect ratio; 1:1, 1:1.3 and 1:2. In this section glazing arrangements are referred to in the following format $[\mathrm{Pr}$, aspect ratio, support conditions] e.g. [27kPa, 1:1, rigid].

Two break parameters quantified glazing failure overall: central deflection at failure and reflected impulse received at break. Glass failure was defined by cracking identified using front-facing camera imagery. Time to failure was calculated as the difference between time of blast arrival (measured from $\operatorname{Pr}$ gauges) and time of glazing failure (from front-facing camera). Reflected impulse was measured at break time from $\operatorname{Pr}$ gauges. Glass panel deflection was measured by tracking a scaled gauge with a high-speed camera. Measurement errors for break time, failure impulse and failure displacement were $\pm 0.01 \mathrm{~ms}, \pm 0.2 \mathrm{kPa}$.ms and $\pm 1 \mathrm{~mm}$ respectively. Failure impulse errors were negligible. The failure displacement error was more significant $( \pm 1 \mathrm{~mm})$ with typical measurements between $10 \mathrm{~mm}$ and $30 \mathrm{~mm}$. This error was due to camera image pixilation and could not be improved without compromising the high frame rate which was required for a precise break time measurement. This error was insignificant when compared to any possible variation in results due to material variability. 


\subsection{PEAK OVERPRESSURE}

Glass panel assemblies with aspect ratio 1:1.7 were disregarded from this analysis as they were only used in higher pressure, $\operatorname{Pr} 27 \mathrm{kPa}$ trials. All break parameters are plotted against $P_{r}$ in Figure 9 to provide an overview of data spread and general trends. For failure deflection, results spread for each reflected pressure was greater (approx. 20mm) and demonstrated consistency between blast environments. Results spread indicated deflection dependency on other parameters (aspect ratio, support conditions and material strength). This trend was independent of $\operatorname{Pr}$ across all blast environments tested. An increase in deflection by $5-10 \mathrm{~mm}$ occurred over a $\mathrm{Pr} 8 \mathrm{kPa}$ increase. Impulse spread was constant (approx. 60kPa.ms) for all blast environments. Impulse at failure increased significantly with $\mathrm{P}_{\mathrm{r}}$, indicating a dependency on $\mathrm{Pr}$.

Influence of the blast environment was quantified by categorising the data into six key structural arrangements, shown in Table 5. Mean parameters were normalised against a result for $\operatorname{Pr} 12 \mathrm{kPa}$ using equation 1 and were plotted in Figure 10. Standard deviation calculations were omitted for single data points.

$$
\text { Normalised break parameter }=\frac{\bar{x}_{P_{r}}}{\bar{x}_{P_{r}=12 k P a}}
$$

The largest normalised displacement increase shown was for aspect ratio 1:1. A $72 \%$ displacement increase was recorded for [1:1, elastic] between reflected pressures, $\operatorname{Pr} 12 \mathrm{kPa}$ and $20 \mathrm{kPa}$. No significant change was measured for [1:1, rigid] between $\operatorname{Pr} 12 \mathrm{kPa}$ and $20 \mathrm{kPa}$ but an increase of $202 \%$ was recorded for $\mathrm{Pr}_{\mathrm{r}}$ increased to $27 \mathrm{kPa}$. Pr exhibited a smaller effect on displacement for all other arrangements. The largest displacement increase was $+34 \%$ for [1:1.3, elastic] between $\operatorname{Pr} 12 \mathrm{kPa}$ and $20 \mathrm{kPa}$. All other normalised displacements were less than 1.20 and shown 
insignificant with respect to standard deviations calculated for each arrangement. No significant trend was determined for these arrangements. Change in displacement was attributed to material variation that was not fully removed from the mean due to the small number of repeats.

All normalised failure impulses increased as $\operatorname{Pr}_{r}$ increased. The largest normalised impulse was for aspect ratio 1:1. Elastically supported glass exhibited a larger normalised impulse for aspect ratios $1: 1$ and 1:1.3 but smaller for 1:2 when compared to rigid framing. All normalised impulses except [1:2, elastic] were larger than 1.20 implying trends were significant compared to standard deviations. Failure impulse increased with reflected pressure, $\mathrm{Pr}_{\mathrm{r}}$ for all arrangements but normalised values were smaller than observed for deflection. The spread of results was small compared to displacement indicating failure impulse was governed by $\operatorname{Pr}$ and structural parameters had less effect. An increased response of windows with aspect ratio 1:1 can be attributed to the symmetrical 2-way spanning arrangement that resulted from a large span. This span governed a reduced window stiffness while more susceptible to increasing rate of impulse due to $\operatorname{Pr}$ producing a higher rate of deflection.

\subsection{ASPECT RATIO}

Four aspect ratios from 1:1 to 1:2 was investigated in blast environment $\operatorname{Pr}$ of $27 \mathrm{kPa}$, three were used in trials with $\mathrm{Pr}_{\mathrm{r}}$ of $20 \mathrm{kPa}$ and $12 \mathrm{kPa}$. Aspect ratio 1:1.7 was not used in these trials. Elastic and rigid support conditions were investigated in trials with blast environment $\operatorname{Pr}$ of $20 \mathrm{kPa}$ and $12 \mathrm{kPa}$, only rigid supports were implemented in $\mathrm{Pr}$ of $27 \mathrm{kPa}$ trials. Mean break parameters and corresponding standard deviations for each arrangement are outlined for reference in Table 6. Mean values were normalised against the 1:1 value to determine the effect of aspect ratio. 
Individual displacement results and the arrangement mean are plotted in Figure

11. For all arrangements aspect ratio 1:1.3 exhibited the largest displacement. For

1:1.7 and 1:2. Different behaviour was observed in glass subjected to $\operatorname{Pr} 20 \mathrm{kPa}$ and $12 \mathrm{kPa}$, displacement for aspect ratio 1:1.3 was greater than 1:1 and 1:2. This trend was exaggerated at $P_{r} 12 \mathrm{kPa}$ than $\operatorname{Pr}_{\mathrm{r}} 20 \mathrm{kPa}$ indicating aspect ratio had a larger effect on displacement at lower overpressures. Aspect ratio exhibited a reduced effect on displacement of elastically supported windows and this effect decreased at lower overpressures. Displacement spread for each arrangement was considerable, the largest standard deviation was $11 \mathrm{~mm}$ for [27kPa, 1:2, rigid]. For some structural arrangements especially at $\operatorname{Pr} 27 \mathrm{kPa}$, the spread was larger than the observed trend. More displacement data from additional blast trials would be required to determine categorically if observed trends were due to aspect ratio or spread of results.

Aspect ratio trends overall were quantified by normalising failure displacements against a reference 1:1 result (see Figure 11). Arrangement [27kPa, rigid] recorded a $15 \%$ increase in displacement from $1: 1$ to $1: 1.3$ but reduced displacements for aspect ratios $1: 1.7$ and $1: 2$ (39\% and $27 \%$ reduction from $1: 1$ result respectively). Normalised displacements for rigid framing were small compared to those from other blast environments. In comparison normalised deflections for [20kPa, 1:1.3, rigid] and [12kPa, 1:1.3, rigid] were 2.96 and 3.15 respectively. Normalised displacement for [1:1.3, rigid] arrangements increased as $P_{r}$ decreased whereas, a reduction was 307 evident for elastically window supports, with a maximum of 1.31 for [12kPa, $1: 1.3$, elastic]. Failure impulse trends were similar to that for deflection (Figure 12). A decrease in impulse as reflected pressure, $\mathrm{Pr}$ decreased was observed. In general, the largest break impulse was recorded for aspect ratio 1:1.3. Results for aspect ratios 
$311 \quad 1: 1$ and 1:2 were similar at lower peak overpressures $(\operatorname{Pr} 20 \mathrm{kPa}$ and $12 \mathrm{kPa})$. For rigidly

312 framed windows the response to aspect ratio $1: 1.3$ increased as $\operatorname{Pr}$ decreased.

313 Normalised break impulses were lower than normalised deflections, but similar trends

314 were observed. The maximum normalised impulse was 1.67 for [12kPa, 1:1.3, rigid]

315 compared to 3.15 for displacement indicating less significance for aspect ratio with respect to failure impulse. For all rigid support arrangements, maximum normalised

317 impulse was recorded for aspect ratio 1:1.3 and increased as $\operatorname{Pr}$ decreased. The largest normalised result for $[27 \mathrm{kPa}$, rigid] was 1.12 suggesting the trend was insignificant compared to standard deviations for this arrangement.

For failure displacement and impulse combined, aspect ratio influence was dependent on support conditions. Aspect ratio exhibited a greater effect on break parameters from rigid support arrays compared to elastic samples. Aspect ratio showed little effect on deflection of rigidly supported glass subjected to $\operatorname{Pr} 27 \mathrm{kPa}$. A decrease in displacement with aspect ratio increase from 1:1.3 to 1:2 can be attributed to a decrease in the shortest glass dimension producing a stiffer one-way spanning arrangement. Aspect ratio 1:1 also exhibited a reduced displacement due to its stiffer two-way spanning installation. Smaller normalised deflections recorded in the $\operatorname{Pr}$ $27 \mathrm{kPa}$ blast environment can be explained by the higher blast pressure punching through the glass. At reduced overpressures, glazing panels were able to deflect and broke due to deflection, allowing aspect ratio to affect glazing behaviour to a higher extent. Elastically supported windows showed smaller normalised deflections 332 indicating aspect ratio was less influential. This can be explained by reduced glass stresses due to elastic framing allowing early rotation, reducing the effect of aspect ratio compared to a clamped rigid frame. The same trends were observed for failure impulse indicating break parameters were closely linked. Aspect ratio 1:1.3 recorded 
the largest normalised impulse for all rigid frames. This trend increased in magnitude as $\operatorname{Pr}$ decreased indicating aspect ratio was more significant at lower $\operatorname{Pr}$ values. Importantly, at lower pressures glazing deflection occurred over a longer time resulting in a larger commensurate influence on structural failure parameters e.g. aspect ratio.

\subsection{SUPPORT CONDITIONS}

Rigid and elastic framing conditions were implemented for $20 \mathrm{kPa} \operatorname{Pr}$ and $12 \mathrm{kPa}$ $\operatorname{Pr}$ blast environments. Only rigid supports were implemented in $\operatorname{Pr} 27 \mathrm{kPa}$ trials therefore results were disregarded from this section. All results are plotted against support conditions, shown in Figure 13. Importantly, two out of six (33\%) elastically supported windows survived when subjected to $\operatorname{Pr} 12 \mathrm{kPa}$. Only one rigidly supported sample (17\%) survived in the same blast environment. Conversely, all samples failed when subjected to $\operatorname{Pr} 20 \mathrm{kPa}$. A small increase in failure displacement was observed for elastically supported glass compared to rigid framing. For both support conditions results spread was shown to be high, $3 \mathrm{~mm}$ to $29 \mathrm{~mm}$ for rigid supports and $8 \mathrm{~mm}$ to $27 \mathrm{~mm}$ for elastic supports. Impulse variance for elastic frames was smaller than rigid supports, indicating rigid framing introduced more inconsistency. This outcome could be attributed to irregular stress concentrations in the glass caused by an uneven frame surface despite ensuring a smooth finish and applying foam tape to protect the glass. There was no significant difference between elastic and rigid mean results for break parameters indicating support conditions had little effect on the mean probability of glass failure.

Mean rigid and elastic results from each arrangement are compared for reference in Table 7 . Mean break parameters for both framing options were normalised against rigid results and plotted in Figure 13. The largest normalised response was for displacement which was 3.23 for [20kPa, 1:1]. Arrangement [12kPa, 
1:1] also recorded a large normalised displacement of 1.81. Results from all other arrangements were significantly smaller. Normalised displacements were greater than one-quarter of the six arrangements, indicating larger observed displacements for elastic frames. Normalised responses for failure impulse were lower than displacement but exhibited a similar key trend. The largest observed was 1.30 for [20kPa, 1:1] and the smallest was 0.85 for arrangement [12kPa, 1:1.3]. Results from remaining arrangements ranged between 0.95 and 1.00 , recording no significant change in impulse between the two support conditions.

Support conditions influenced failure displacement more than blast impulse. Elastic framing gave rise to the largest increase in deflection for arrangements with aspect ratio 1:1. Response was greater for reflected pressures, $\operatorname{Pr} 20 \mathrm{kPa}$ than $12 \mathrm{kPa}$. Normalised deflection remained low for all other aspect ratios, between 0.75 and 1.18 with an even number of results above and below 1.00 indicating support conditions had little influence on outcome. Failure impulse followed the same trends identified for deflection, windows with aspect ratio 1:1 recorded the largest normalised impulse.

\subsection{STRUCTURAL PARAMETER SIGNIFICANCE}

The significance of each structural parameter was determined from the magnitude of the range identified. Range was defined as the difference between maximum and minimum mean values for an arrangement (see Figure 14). In this example the effect of aspect ratio on failure displacement was quantified for arrangement $[27 \mathrm{kPa}$, rigid]. The largest mean value was $25 \mathrm{~mm}$ and the smallest $14 \mathrm{~mm}$, producing a spread of $11 \mathrm{~mm}$. This displacement range due to material variability was plotted for all arrangements with the maximum value coloured black (Figure 15). Each displacement range for aspect ratio was plotted in Figures 15 \& 15c. The largest value was highlighted in red. The process was repeated for support 
conditions and $\mathrm{Pr}_{\mathrm{r}}$. Mean values reduced spread of results due to material variability.

387 The significance of this intrinsic variability was determined by finding the spread (e.g. displacement range) between experimental repeats of the same arrangement, shown in red in Figure 15a. Maximum and mean values for each structural parameter were compared in part (d) of the figure to determine the most significant parameter. The process was repeated for failure impulse (Figure 16). Four repeats were completed for all arrangements subjected to $\operatorname{Pr} 27 \mathrm{kPa}$ but only two repeats for alternative blast environments. One window remained unbroken from arrangements [12kPa, 1:1, elastic], [12kPa, 1:1.3, rigid] and [12kPa, 1:2, elastic] resulting in zero material variation range.

The largest displacement spread due to material variability was $26 \mathrm{~mm}$ for [27kPa, 1:1, rigid]. For rigid support conditions all blast environments were considered, elastic framing was only tested in blast environments $\operatorname{Pr} 20 \mathrm{kPa}$ and $12 \mathrm{kPa}$ (Figure 15b). The largest displacement spread was $15 \mathrm{~mm}$ for [1:1, rigid]. Displacement range for elastic supports was smaller than rigid which was attributed to elastic supports not being tested at $\operatorname{Pr} 27 \mathrm{kPa}$. Displacement variation decreased as aspect ratio increased for both support conditions, implying $\mathrm{P}_{\mathrm{r}}$ had a reduced impact on displacement at higher aspect ratios. The largest displacement range for aspect ratio was $16 \mathrm{~mm}$ for [12kPa, rigid]. Rigidly supported glass exhibited larger displacement ranges than equivalent elastic arrangements indicating aspect ratio exhibited a greater effect on rigid framing. Aspect ratio and displacement spread increased as $\operatorname{Pr}$ conversely decreased indicating higher sensitivity to aspect ratio at lower overpressures for rigid supports. Importantly, elastic framing recorded the opposite effect; displacement variation reduced as $\mathrm{Pr}_{\mathrm{r}}$ decreased. Displacement spread for support conditions was

410 significantly lower than aspect ratio or Pr. The maximum was $16 \mathrm{~mm}$ for [20kPa, 1:1]. 
411 Maximum and mean displacement ranges for each parameter are shown in Figure

412 15e. Little difference between maximum deflection ranges was observed. Material 413 variation exhibited a higher maximum variation $(26 \mathrm{~mm})$. Considering mean values, 414 aspect ratio had the largest influence on displacement $(11 \mathrm{~mm})$, compared to material 415 variability $(9 \mathrm{~mm}), \operatorname{Pr}(7 \mathrm{~mm})$ and support conditions $(6 \mathrm{~mm})$. Over all arrangements 416 experimentally tested, aspect ratio was shown to be the most significant parameter 417 when considering glazing displacement at failure. Effect of material variation was also commensurately significant.

The largest failure impulse range due to material variation was $53 \mathrm{kPa} . \mathrm{ms}$ for $420[27 \mathrm{kPa}, 1: 1$, rigid] (Figure 16a). The largest impulse spread due to $\operatorname{Pr}$ was $88 \mathrm{kPa} . \mathrm{ms}$ 421 for [1:1, rigid] (Figure 16b). All impulse ranges for rigid supports were larger than equivalent elastic samples. It should be noted that elastic supports were not used in trials with $\operatorname{Pr} 27 \mathrm{kPa}$. Impulse variation for elastic frames decreased as aspect ratio increased indicating $\mathrm{P}_{\mathrm{r}}$ was less significant at higher aspect ratios for elastic support conditions. A similar trend was not observed for rigid supports. Break impulse ranges due to aspect ratio were much smaller than those due to $P_{r}$. The largest spread was 38kPa.ms for [12kPa, rigid]. For rigid framing, break impulse variation increased as $\operatorname{Pr}$ decreased. This indicated increased aspect ratio significance at lower $\operatorname{Pr}$ values. The opposite effect was recorded for elastic framing, impulse ranges decreased with $\mathrm{Pr}$ increase. Break impulse ranges for support conditions were much smaller than other parameters (maximum 26kPa.ms for [20kPa, 1:1]).

Support conditions gave rise to lower sensitivity with respect to glazing aspect ratios. Results showed that support framing effects were independent of aspect ratio for $\operatorname{Pr} 12 \mathrm{kPa}$. Reflected overpressure was consistently the parameter with the largest 
435 effect on break impulse (maximum spread $88 \mathrm{kPa} . \mathrm{ms}$ and mean range 52kPa.ms).

436 Material variability produced the second largest variance but a smaller overall mean.

\section{CONCLUSIONS}

In total, 40 window structures were tested in 20 individual air blast trials. Importantly, the blast environment in the $A B T$ was shown to be highly consistent across all trials with the largest total reflected impulse standard deviation at just $2 \%$ of

441 the mean. Reflected overpressure histories exhibited good consistency between trials, 442 providing reliable loading and accurate impulse measurements, an important and key consideration with respect to repeats and scientific rigour. Three out of twelve windows subjected to peak reflected overpressure of $12 \mathrm{kPa}$ survived, all other windows failed. There was no trend in window survival, indicating material variation was the root cause. It was concluded that a pressure, $\operatorname{Pr}$ of $12 \mathrm{kPa}$ was close to the survival 447 threshold for $4 \mathrm{~mm}$ thick annealed glass with area $0.89 \mathrm{~m}^{2}$. It was determined that 448 failure displacement was dependent on aspect ratio and material variability whereas 449 failure impulse was governed by the blast environment. Experimental observation showed support conditions had minimal effect on failure behaviour.

Trends within break parameter ranges indicated all components were interlinked and glazing behaviour was dependent on a complex non-deterministic combination.

453 Importantly, experimental repeats in this paper exhibit notable data spread, demonstrating that glazing response is highly variable therefore repeat data are critical. Where budget constraints prevent repeat data, consideration should be given to the representativeness of test data and benchmarking of further research should be

457 undertaken with caution. Reliance upon legacy pressure-impulse diagrams or 458 methods should be re-examined as a priority; particularly given their deterministic 
approach and poor scope for parameter inclusion e.g. geometric size, supports or material variability. Repeat (reference) data sets in this paper provide considerable scientific value to both practitioners and researchers particularly in this costly and difficult field of engineering where access to suitable test facilities remain limited.

\section{ACKNOWLEDGEMENTS}

The authors would like to express gratitude to the UK Ministry of Defence for allowing use of the blast testing facilities at MOD Shoeburyness. All data obtained whilst using these facilities remain the property of the UK MOD. Permission to utilize these results within this paper is gratefully acknowledged. This work was supported by AWE PIc and the Engineering and Physical Sciences Research Council (EPSRC) [grant number 1636607].

\section{REFERENCES}

[1] H.S. Norville, N. Harvill, E.J. Conrath, S. Shariat, S. Mallonee, Glass-Related Injuries in Oklahoma City Bombing, J. Perform. Constr. Facil. 13 (1999) 50-56. https://doi.org/10.1061/(asce)0887-3828(2000)14:4(167).

[2] E. Trawinski, J.W. Fisher, R.J. Dinan, J. Fisher, R. Dinan, AFRL-ML-TY-TP-2005-4508 Full Scale Testing of Polymer Reinforced Blast Resistant Windows, Florida, USA, 2005.

[3] K.J. Claber, Designing window glazing for explosive loading, Proc. - Int. Carnahan Conf. Secur. Technol. (1998) 65-72. https://doi.org/10.1109/CCST.1998.723768.

[4] S.E. Rigby, T.J. Lodge, S. Alotaibi, A.D. Barr, S.D. Clarke, G.S. Langdon, A. Tyas, Preliminary yield estimation of the 2020 Beirut explosion using video footage from social media, Shock Waves. 30 (2020) 671-675. https://doi.org/10.1007/s00193-020-00970Z.

[5] P. Huang, J. Zhang, Facts Related to August 12, 2015 Explosion Accident in Tianjin, China, Process Saf. Prog. 34 (2015).

[6] S.L. McGarry, S. Balsari, S. Muqueeth, J. Leaning, Preventing the Preventable: The 2015 Tianjin Explosions, Cambridge, MA, 2017. http://www.hkjcdpri.org.hk/download/casestudies/Tianjin_CASE.pdf. 
487 [7] BBC News, China explosions: What we know about what happened in Tianjin, (2015). http://www.bbc.co.uk/news/world-asia-china-33844084 (accessed February 2, 2016).

489 [8] W.L. Beason, J.R. Morgan, Glass failure prediction model, J. Struct. Eng. (United States). $110 \quad$ (1984) 197-212. https://doi.org/10.1061/(ASCE)07339445(1985)111:9(2059).

[9] British Standards Institution, BS EN 572-1:2012: Glass in building - Basic soda lime silicate glass products - Part 1: Definitions and general physical and mechanical properties, (2012). https://www.bsigroup.com/.

[10] W.C. Clark, The effect of atomic weapons on glazing and window construction, United States Atomic Energy Commission, Washington D.C., 1955.

497

[11] P.A. Randall, Damage to Conventional and Special Types of Residences Exposed to 498 Nuclear Effects, United States Atomic Energy Commission, Washington D.C., 1961. https://doi.org/10.2172/4029823.

501

502

[12] C.A.B. Chilton, Resistance of Glass Windows to Atomic Blast, in: Department Of the Navy (Ed.), Stud. At. Def. Eng., Department of the Navy, Bureau of Yards and Docks,

503 Washington D.C., 1962.

504

[13] E.R. Fletcher, D.R. Richmond, R.K. Jones, Air blast effects on windows in buildings and $505 \quad 251-275$. automobiles on the Eskimo II Event, Minutes 15th Explos. Saf. Semin. - Vol. 1. (1973)

506

[14] S.K. Clubley, Non-linear long duration blast loading of cylindrical shell structures, Eng. Struct. 59 (2014) 113-126. https://doi.org/10.1016/j.engstruct.2013.10.030.

[15] R. Johns, Investigating Annealed Glazing Response to Long-Duration Blast, PhD 509 Thesis. University of Southampton, 2016.

[16] R. V. Johns, S.K. Clubley, The influence of structural arrangement on long-duration blast response of annealed glazing, Int. J. Solids Struct. 97-98 (2016) 370-388. https://doi.org/10.1016/j.ijsolstr.2016.07.012.

[17] M. Nawar, H. Salim, B. Lusk, S. Kiger, Modeling and Shock Tube Testing of Architectural Glazing Systems for Blast Resistance, J. Struct. Eng. 141 (2015) 04014174: 1-9. https://doi.org/10.1061/(ASCE)ST.1943-541X.0001130.

[18] P.A. Hooper, R.A.M. Sukhram, B.R.K. Blackman, J.P. Dear, On the blast resistance of laminated glass, Int. J. Solids Struct. $49 \quad$ (2012) 899-918. https://doi.org/10.1016/j.ijsolstr.2011.12.008. 
and Testing of Laminated Window Systems under Blast Loading, in: A.S. of C. Engineers (Ed.), Struct. Congr., Las Vagas, Nevada, 2011: pp. 1552-1560.

[20] S. Chen, C.G. Zhu, G.Q. Li, Y. Lu, Blast test and numerical simulation of pointsupported glazing, Adv. Struct. Eng. 19 (2016) 1841-1854. https://doi.org/10.1177/1369433216649387.

[21] J. Wei, L.R. Dharani, Fracture mechanics of laminated glass subjected to blast loading, Theor. Appl. Fract. Mech. $44 \quad$ (2005) 157-167. https://doi.org/10.1016/j.tafmec.2005.06.004.

[22] J. Wei, M.S. Shetty, L.R. Dharani, Failure analysis of architectural glazing subjected to blast loading, Eng. Fail. Anal. $13 \quad$ (2006) 1029-1043. https://doi.org/10.1016/j.engfailanal.2005.07.010.

[23] X. Zhang, H. Hao, Z. Wang, Experimental Investigation on Monolithic Tempered Glass Window Responses to Blast Loads, Int. J. Prot. Struct. 6 (2015) 287-309. https://doi.org/10.1260/2041-4196.6.2.287. 
5358 TABLES

536 Table 1. Dynamic trials specification

\begin{tabular}{|c|c|c|c|c|c|c|}
\hline & Trial & Design $P_{s}$ & & Glass Dimensions & Support & $\begin{array}{c}\text { No. } \\
\text { Windows }\end{array}$ \\
\hline Phase & No. & $(\mathrm{kPa})$ & Aspect Ratio & {$[x: y](m m)$} & Conditions & in Trial \\
\hline \multirow[t]{8}{*}{1} & 1 & 14 & $1: 1$ & {$[945: 945]$} & Rigid & 2 \\
\hline & 2 & 14 & $1: 1.3$ & [827:1075] & Rigid & 2 \\
\hline & 3 & 14 & $1: 1.7$ & [725:1230] & Rigid & 2 \\
\hline & 4 & 14 & $1: 2$ & {$[667: 1334]$} & Rigid & 2 \\
\hline & 5 & 14 & $1: 1$ & {$[945: 945]$} & Rigid & 2 \\
\hline & 6 & 14 & $1: 1.3$ & [827:1075] & Rigid & 2 \\
\hline & 7 & 14 & $1: 1.7$ & {$[725: 1230]$} & Rigid & 2 \\
\hline & 8 & 14 & $1: 2$ & [667:1334] & Rigid & 2 \\
\hline \multirow[t]{12}{*}{2} & 9 & 10 & $1: 1$ & [945:945] & Rigid & 2 \\
\hline & 10 & 10 & $1: 1$ & [945:945] & Elastic & 2 \\
\hline & 11 & 10 & $1: 1.3$ & {$[827: 1075]$} & Rigid & 2 \\
\hline & 12 & 10 & $1: 1.3$ & [827:1075] & Elastic & 2 \\
\hline & 13 & 10 & $1: 2$ & [667:1334] & Rigid & 2 \\
\hline & 14 & 10 & $1: 2$ & {$[667: 1334]$} & Elastic & 2 \\
\hline & 15 & 5 & $1: 1$ & [945:945] & Rigid & 2 \\
\hline & 16 & 5 & $1: 1$ & {$[945: 945]$} & Elastic & 2 \\
\hline & 17 & 5 & $1: 1.3$ & [827:1075] & Rigid & 2 \\
\hline & 18 & 5 & $1: 1.3$ & {$[827: 1075]$} & Elastic & 2 \\
\hline & 19 & 5 & $1: 2$ & {$[667: 1334]$} & Rigid & 2 \\
\hline & 20 & 5 & $1: 2$ & [667:1334] & Elastic & 2 \\
\hline
\end{tabular}

537

538 
539 Table 2. Free-field blast parameters for all trials.

\begin{tabular}{|c|c|c|c|c|c|c|c|c|c|c|c|}
\hline Design $P_{s}$ & Trial No. & 1 & 2 & 3 & 4 & 5 & 6 & 7 & 8 & $\overline{\mathrm{x}}$ & $\sigma$ \\
\hline \multirow[t]{3}{*}{$14 \mathrm{kPa}$} & $\mathrm{P}_{\mathrm{s}}(\mathrm{kPa})$ & 13.4 & 13.3 & 13.5 & 13.5 & 13.4 & 13.5 & 13.5 & 13.1 & 13.4 & 0.1 \\
\hline & $\mathrm{t}_{\mathrm{d}}(\mathrm{ms})$ & 101 & 102 & 100 & 99 & 100 & 99 & 101 & 100 & 100 & 1 \\
\hline & $\mathrm{I}_{\mathrm{s}}$ (kPa.ms) & 701 & 693 & 681 & 691 & 681 & 694 & 697 & 683 & 690 & 7 \\
\hline Design $P_{s}$ & Trial No. & 9 & 10 & 11 & 12 & 13 & 14 & & & $\overline{\mathrm{x}}$ & $\sigma$ \\
\hline \multirow[t]{3}{*}{$10 \mathrm{kPa}$} & $P_{s}(k P a)$ & 10.4 & 10.3 & 10.2 & 10.3 & 9.9 & 9.7 & & & 10.1 & 0.2 \\
\hline & $\mathrm{t}_{\mathrm{d}}(\mathrm{ms})$ & 74 & 74 & 73 & 74 & 74 & 75 & & & 74 & 1 \\
\hline & $\mathrm{I}_{\mathrm{s}}$ (kPa.ms) & 452 & 443 & 442 & 443 & 439 & 431 & & & 442 & 6 \\
\hline Design $P_{s}$ & Trial No. & 15 & 16 & 17 & 18 & 19 & 20 & & & $\overline{\mathrm{x}}$ & $\sigma$ \\
\hline \multirow[t]{3}{*}{$5 \mathrm{kPa}$} & $\mathrm{P}_{\mathrm{s}}(\mathrm{kPa})$ & 6.1 & 6.0 & 6.1 & 6.6 & 6.0 & 6.7 & & & 6.3 & 0.3 \\
\hline & $t_{d}(m s)$ & 49 & 48 & 48 & 49 & 49 & 47 & & & 48 & 1 \\
\hline & $\mathrm{I}_{\mathrm{s}}$ (kPa.ms) & 222 & 217 & 220 & 226 & 228 & 223 & & & 223 & 4 \\
\hline
\end{tabular}

540

541 
542 Table 3. Reflected blast parameters for all trials.

\begin{tabular}{|c|c|c|c|c|c|c|c|c|c|c|c|}
\hline \multicolumn{12}{|c|}{ Design $\mathrm{P}_{\mathrm{s}} 14 \mathrm{kPa}$} \\
\hline Trial No. & Cubicle & 1 & 2 & 3 & 4 & 5 & 6 & 7 & 8 & $\overline{\mathbf{x}}$ & $\sigma$ \\
\hline \multirow[t]{2}{*}{$\operatorname{Pr}(\mathrm{kPa})$} & $A$ & 26.1 & 25.9 & 26.7 & 26.6 & 26.3 & 26.7 & 27.5 & 26.1 & \multirow{2}{*}{27.2} & \multirow{2}{*}{0.9} \\
\hline & $B$ & 26.8 & 26.9 & 28.2 & 28.6 & 27.7 & 28.7 & 28.8 & 27.5 & & \\
\hline \multirow[t]{2}{*}{$I_{r}$ (kPa.ms) } & $A$ & 734 & 738 & 716 & 725 & 715 & 729 & 728 & 717 & \multirow{2}{*}{724} & \multirow{2}{*}{8} \\
\hline & B & 734 & 735 & 715 & 723 & 712 & 726 & 727 & 716 & & \\
\hline \multicolumn{12}{|c|}{ Design $\mathrm{P}_{\mathrm{s}} 10 \mathrm{kPa}$} \\
\hline Trial No. & Cubicle & 9 & 10 & 11 & 12 & 13 & 14 & & & $\overline{\mathbf{x}}$ & $\sigma$ \\
\hline \multirow[t]{2}{*}{$\operatorname{Pr}(\mathrm{kPa})$} & $A$ & 20.5 & 20.4 & 20.2 & 20.3 & 18.9 & 18.0 & & & \multirow{2}{*}{20.1} & \multirow{2}{*}{1.0} \\
\hline & B & 21.2 & 21.2 & 20.7 & 20.9 & 19.4 & 19.2 & & & & \\
\hline \multirow[t]{2}{*}{$I_{r}$ (kPa.ms) } & $A$ & 450 & 441 & 439 & 440 & 437 & 429 & & & \multirow{2}{*}{435} & \multirow{2}{*}{7} \\
\hline & B & 441 & 432 & 431 & 434 & 427 & 423 & & & & \\
\hline \multicolumn{12}{|c|}{ Design $\mathrm{P}_{\mathrm{s}} 5 \mathrm{kPa}$} \\
\hline Trial No. & Cubicle & 15 & 16 & 17 & 18 & 19 & 20 & & & $\overline{\mathbf{x}}$ & $\sigma$ \\
\hline \multirow[t]{2}{*}{$\operatorname{Pr}(\mathrm{kPa})$} & $A$ & 12.4 & 12.0 & 11.9 & 13.1 & 11.4 & 13.5 & & & \multirow{2}{*}{12.4} & \multirow{2}{*}{0.7} \\
\hline & B & 12.1 & 11.9 & 11.8 & 13.5 & 11.7 & 13.5 & & & & \\
\hline \multirow[t]{2}{*}{$I_{r}$ (kPa.ms) } & $A$ & 222 & 212 & 215 & 225 & 228 & 220 & & & \multirow{2}{*}{219} & \multirow{2}{*}{5} \\
\hline & B & 220 & 213 & 212 & 220 & 226 & 217 & & & & \\
\hline
\end{tabular}

543

544 
545 Table 4. Pr values quoted in reference to blast environments for all glazing analyses.

\begin{tabular}{lccc}
\hline Design $\mathrm{P}_{\mathrm{s}}(\mathrm{kPa})$ & 5 & 10 & 14 \\
Mean $\mathrm{Pr}_{\mathrm{r}}(\mathrm{kPa})$ & 12 & 20 & 27 \\
\hline
\end{tabular}

546

547 
548 Table 5. Summary: break parameters as a function of $\mathrm{Pr}$.

\begin{tabular}{lllllllll}
\hline Aspect & Support & $\operatorname{Pr}_{\mathrm{r}}(\mathrm{kPa})$ & \multicolumn{3}{c}{ Failure Displacement $(\mathrm{mm})$} & \multicolumn{2}{c}{ Failure Impulse (kPa.ms) } \\
\cline { 6 - 9 } Ratio & Condition & & $\overline{\mathrm{x}}$ & $\sigma$ & Norm & $\overline{\mathrm{x}}$ & $\sigma$ & Norm \\
\hline $1: 1$ & Rigid & 12 & 7 & 4 & 1.00 & 57 & 10 & 1.00 \\
$1: 1$ & Rigid & 20 & 7 & 0 & 0.97 & 90 & 9 & 1.57 \\
$1: 1$ & Rigid & 27 & 22 & 9 & 1.00 & 145 & 19 & 2.54 \\
\hline $1: 1$ & Elastic & 12 & 13 & - & 1.00 & 67 & - & 1.00 \\
$1: 1$ & Elastic & 20 & 23 & 1 & 1.72 & 116 & 9 & 1.73 \\
\hline $1: 1.3$ & Rigid & 12 & 23 & - & 1.00 & 95 & - & 1.00 \\
$1: 1.3$ & Rigid & 20 & 21 & 8 & 0.91 & 118 & 22 & 1.24 \\
$1: 1.3$ & Rigid & 27 & 25 & 3 & 1.10 & 153 & 6 & 1.61 \\
\hline $1: 1.3$ & Elastic & 12 & 17 & 1 & 1.00 & 81 & 5 & 1.00 \\
$1: 1.3$ & Elastic & 20 & 23 & 4 & 1.34 & 115 & 7 & 1.41 \\
\hline $1: 2$ & Rigid & 12 & 14 & 11 & 1.00 & 64 & 22 & 1.00 \\
$1: 2$ & Rigid & 20 & 15 & 4 & 1.05 & 96 & 6 & 1.50 \\
$1: 2$ & Rigid & 27 & 16 & 4 & 1.16 & 132 & 13 & 2.07 \\
\hline $1: 2$ & Elastic & 12 & 16 & - & 1.00 & 78 & - & 1.00 \\
$1: 2$ & Elastic & 20 & 13 & 5 & 0.82 & 92 & 16 & 1.17 \\
\hline & & & & & & & & \\
\hline
\end{tabular}

549 Norm - Break parameter normalised against result for $12 \mathrm{kPa}$.

550 Dash indicates no standard deviation due to sample size of one. 
552 Table 6. Summary: break parameters as a function of aspect ratio.

\begin{tabular}{lcccccccc}
\hline Support & $\mathrm{P}_{\mathrm{r}}$ & Aspect Ratio & \multicolumn{3}{c}{ Failure Displacement $(\mathrm{mm})$} & \multicolumn{3}{c}{ Failure } \\
\cline { 5 - 9 } Condition & $(\mathrm{kPa})$ & & $\overline{\mathrm{x}}$ & $\sigma$ & Norm & $\overline{\mathrm{x}}$ & $\sigma$ & Norm \\
\hline Rigid & 27 & 1 & 22 & 9 & 1.00 & 145 & 19 & 1.00 \\
Rigid & 27 & 1.3 & 25 & 3 & 1.15 & 153 & 6 & 1.06 \\
Rigid & 27 & 1.7 & 14 & 6 & 0.61 & 128 & 11 & 0.88 \\
Rigid & 27 & 2 & 16 & 4 & 0.73 & 132 & 13 & 0.91 \\
\hline Rigid & 20 & 1 & 7 & 0 & 1.00 & 90 & 9 & 1.00 \\
Rigid & 20 & 1.3 & 21 & 8 & 2.96 & 118 & 22 & 1.31 \\
Rigid & 20 & 2 & 15 & 4 & 2.06 & 96 & 6 & 1.07 \\
\hline Rigid & 12 & 1 & 7 & 4 & 1.00 & 57 & 10 & 1.00 \\
Rigid & 12 & 1.3 & 23 & - & 3.15 & 95 & - & 1.67 \\
Rigid & 12 & 2 & 14 & 11 & 1.90 & 64 & 22 & 1.11 \\
\hline Elastic & 20 & 1 & 23 & 1 & 1.00 & 116 & 9 & 1.00 \\
Elastic & 20 & 1.3 & 23 & 4 & 1.01 & 115 & 7 & 0.99 \\
Elastic & 20 & 2 & 13 & 5 & 0.59 & 92 & 16 & 0.79 \\
\hline Elastic & 12 & 1 & 13 & - & 1.00 & 67 & - & 1.00 \\
Elastic & 12 & 1.3 & 17 & 1 & 1.31 & 81 & 5 & 1.21 \\
Elastic & 12 & 2 & 16 & - & 1.24 & 78 & - & 1.16 \\
\hline & & & & & & & & \\
\hline
\end{tabular}

553 Norm - Break parameter normalised against result for 1:1.

554 Dash indicates no standard deviation due to sample size of one. 
556 Table 7. Summary: break parameters as a function of support conditions.

\begin{tabular}{|c|c|c|c|c|c|c|c|c|}
\hline \multirow{2}{*}{$\begin{array}{c}\mathrm{Pr}_{\mathrm{r}} \\
(\mathrm{kPa})\end{array}$} & \multirow{2}{*}{$\begin{array}{l}\text { Aspect } \\
\text { Ratio }\end{array}$} & \multirow{2}{*}{$\begin{array}{l}\text { Support } \\
\text { Condition }\end{array}$} & \multicolumn{3}{|c|}{ Failure Displacement (mm) } & \multicolumn{3}{|c|}{ Failure Impulse (kPa.ms) } \\
\hline & & & $\overline{\mathrm{x}}$ & $\sigma$ & Norm & $\overline{\mathrm{x}}$ & $\sigma$ & Norm \\
\hline \multirow[t]{2}{*}{12} & 1 & Rigid & 7 & 4 & 1.00 & 57 & 10 & 1.00 \\
\hline & & Elastic & 13 & - & 1.81 & 67 & - & 1.18 \\
\hline \multirow[t]{2}{*}{12} & 1.3 & Rigid & 23 & - & 1.00 & 95 & - & 1.00 \\
\hline & & Elastic & 17 & 1 & 0.75 & 81 & 5 & 0.85 \\
\hline \multirow[t]{2}{*}{12} & 2 & Rigid & 14 & 11 & 1.00 & 64 & 22 & 1.00 \\
\hline & & Elastic & 16 & - & 1.18 & 78 & - & 1.23 \\
\hline \multirow[t]{2}{*}{20} & 1 & Rigid & 7 & 0 & 1.00 & 90 & 9 & 1.00 \\
\hline & & Elastic & 23 & 1 & 3.23 & 116 & 9 & 1.30 \\
\hline \multirow[t]{2}{*}{20} & 1.3 & Rigid & 21 & 8 & 1.00 & 118 & 22 & 1.00 \\
\hline & & Elastic & 23 & 4 & 1.10 & 115 & 7 & 0.97 \\
\hline \multirow[t]{2}{*}{20} & 2 & Rigid & 15 & 4 & 1.00 & 96 & 6 & 1.00 \\
\hline & & Elastic & 13 & 5 & 0.92 & 92 & 16 & 0.96 \\
\hline
\end{tabular}

557 Norm - Results normalised against rigid framing.

558 Dash indicates no standard deviation due to sample size of one.

559 